\title{
THE OPTIMIZATION OF PEPTIDES - PRODUCING CONDITIONS FOR ANTIOXIDANT PEPTIDES IN GOAT MILK BY LACTOBACILLUS CASEI L61
}

\author{
He Chen ${ }^{1 凶}$, Yaolong $\mathrm{Mao}^{1}$, Guanli $\mathrm{Du}^{2}$, Xiangyun $\mathrm{Li}^{2}$, Zemin $\mathrm{Li}^{2}$, Jianbo Kou${ }^{1}$ \\ ${ }^{1}$ School of Food and Biological Engineering, Shaanxi University of Science and Technology \\ Xuefu Middle 6, 710021 Xi'an, Weiyang district, China \\ ${ }^{2}$ Department of Research and Development, Xi'an Xiyangyang Biological Technology Co. \\ Xi'an, China
}

\begin{abstract}
Background. The chemical synthesis of antioxidants has exposed more and more of their disadvantages. Therefore, the development of safe, healthy and efficient natural antioxidants has become a research hotspot. At present, antioxidant peptides are gradually becoming more popular due to their strong antioxidant activity and high safety.

Materials and methods. The aim of this experiment was to obtain the optimum fermentation conditions for producing antioxidant peptides from Lactobacillus casei L61. The effects of various factors (fermentation temperature, fermentation time, concentration of regenerated milk and inoculum) on the production of antioxidant peptides by Lactobacillus casei L61 were studied using a single factor test. Four methods (DPPH radical scavenging activity, the ability to chelate iron, hydroxyl radical scavenging rate, total reduction force) were used to determine antioxidant activity in vitro. The optimum fermentation conditions were determined by orthogonal experiment.

Results. The results showed that the optimal fermentation conditions for the production of antioxidant peptides by L61 were $11 \%$ reconstituted milk, $5 \%$ inoculated milk, fermentation at $41^{\circ} \mathrm{C}$ and 16 hours of fermentation time. Under these conditions, the results of the orthogonal test showed that the DPPH radical scavenging rate of the whey sample was $59.97 \pm 0.87 \%$, which was higher than those of the other 9 groups, and significantly higher than that of the control group $(41.97 \pm 1.37 \%)$.

Conclusion. The concentration of reconstituted milk and the amount of inoculated milk had a significant effect on the production of antioxidant peptides by Lactobacillus casei L61. It provides a reference for the optimization of the fermentation nutritional composition of antioxidant peptides produced by Lactobacillus casei L61.
\end{abstract}

Keywords: goat milk, antioxidant peptide, fermentation, Lactobacillus casei

Funding: The Key Research and Development Program of Shaanxi (Program No. 2019ZDLNY06-03).

『2739854893@qq.com, https://orcid.org/0000-0001-6046-7583, phone 0086 15619239983, fax 008686168293 


\section{INTRODUCTION}

Harman theorized about free radicals in the middle of the last century, and since then it has been found that free radicals accumulate in the body during many diseases, including heart disease, diabetes, cancer, cataracts, and aging (Harman, 2006). They have a strong oxidation capacity in the body, and when the body produces too many free radicals, it will cause a serious impact on the organs and tissues of the body (Das, 2016). Studies have found that free radicals produced by oxidation can attack proteins and nucleic acids, causing cell damage and breaking the balance of the body's antioxidant defense system, leading to diseases in the body. Therefore, it is necessary to take in exogenous antioxidants to remove free radicals in the body (Clancy and Birdsall, 2013; Park et al., 2001; Persichetti et al., 2014; Sila and Bougatef, 2016).

In recent years, with the continuous improvement of human research and knowledge, more and more disadvantages of the chemical synthesis of antioxidants have been exposed (Goodman et al., 1990). Therefore, the development of safe, healthy and efficient natural antioxidants has become a research hotspot. Nowadays, antioxidant peptides are gradually becoming more popular on account of their strong oxidation resistance and high safety, and have shown excellent prospects for application in food, medicine and other fields. The antioxidant peptide is an important biological peptide belonging to a special protein fragment with a low molecular weight and strong antioxidant capacity, which can effectively remove free radicals accumulated in the body (Abeyrathne et al., 2018; Kitts and Weiler, 2003). In general, antioxidant peptides are unable to express their activity normally, but they can be released by enzymatic hydrolysis or fermentation, showing specific functions (Lorenzo et al., 2018). Compared with enzymatic hydrolysis, fermentation has the advantages of a lower cost, higher yield and more convenient operation. At present, the preparation of antioxidant peptides from milk is mainly by enzymolysis at home and abroad, but research on the preparation of antioxidant peptides by probiotic fermentation is lacking. At the moment, some scholars have screened Lactobacillus fermentum M4, Lactobacillus acidophilus TS2004, Lactobacillus suis ASCC983, Lactobacillus bulgaricus 134.5 and
Streptococcus thermophilus SP1.1, and determined the best conditions for producing peptides (Bao et al., 2009; Elfahri et al., 2016; Guo, 2003; Panchal et al., 2020; Ramesh et al., 2012; Virtanen et al., 2007). In this study, a single factor test was used to investigate the effects of fermentation time, fermentation temperature, inoculum and concentration of reconstituted milk on the production of antioxidant peptides in fermented goat milk, and the single factor optimum conditions were obtained. A four-factor and three-level orthogonal test was designed to determine the optimum production process conditions, which laid a foundation for subsequent experiments.

\section{MATERIALS AND METHOD}

\section{Microorganism and growth medium}

Microorganism. Lactobacillus casei L61 was obtained from the College of Food and Biological Engineering, Shaanxi University of Science and Technology (Xi'an, China).

Strain activation. The strain was inoculated three successive times with the MRS medium at $37^{\circ} \mathrm{C}$ for $24 \mathrm{~h}$ until the viability of the bacteria remained stable. The third-generation bacteria solution obtained above was inoculated in a medium of reconstituted goat milk according to $5 \%(\mathrm{v} / \mathrm{v})$. After fully mixing, it was fermented in a constant temperature incubator at $37^{\circ} \mathrm{C}$ to complete curdling, and then stored in a refrigerator at $4^{\circ} \mathrm{C}$ for standby.

Preparation of the fermented goat milk and whey samples. The reconstituted milk with the required concentration of skimmed goat milk powder was pasteurized at $95^{\circ} \mathrm{C}$ for 15 minutes. After it was cooled, it was inoculated with the activated bacteria according to a specific amount of inoculation and fermented in a constant temperature water bath at a specific temperature. After the fermentation, the fermented milk was taken out for testing.

The obtained fermented milk was shaken and poured into a $100 \mathrm{~mL}$ clean beaker to measure the $\mathrm{pH}$ value of the fermented milk. First, the fermented milk was adjusted to $3.4-3.6$ with $\mathrm{HCl}(1 \mathrm{~mol} / \mathrm{L})$. After centrifugation at $5000 \times \mathrm{g}$ for 15 minutes, the supernatant 
was collected and adjusted to $\mathrm{pH} 8.3$ with $\mathrm{NaOH}$ $(1 \mathrm{~mol} / \mathrm{L})$ and centrifuged at $5000 \times \mathrm{g}$ for 15 minutes. The supernatant was collected as the whey sample for the determination of antioxidant activity (Shu et al., 2019).

\section{In vitro antioxidant assay}

There are many methods for evaluating the antioxidation in vitro, but the principles are different and the results may not be the same. Therefore, the combination of various methods can evaluate the antioxidant capacity comprehensively and accurately. Therefore, this study adopted several commonly used methods to detect the antioxidant activity, and evaluate the antioxidant peptide activity.

DPPH radical scavenging activity. $2.0 \mathrm{~mL}$ of the sample was taken to be tested and placed in a test tube. DPPH ethanol solution $(0.1 \mathrm{mmol} / \mathrm{L})$ of equal volume was added, and mixed thoroughly in a whirlpool mixer. It was then incubated at $25^{\circ} \mathrm{C}$ in the dark for 30 min. Finally, the absorbance of the reaction solution was measured at $517 \mathrm{~nm}$. The calculation formula is as follows (Zeng et al., 2012):

DPPH radical scavenging activity $=\left(1-\frac{A_{1}-A_{2}}{A_{3}}\right) \times 100$ where:

$A_{1}$ - the absorbance of the sample group,

$A_{2}$ - the absorbance of the blank group containing $2 \mathrm{~mL} \mathrm{95 \%} \mathrm{ethanol} \mathrm{and} 2 \mathrm{~mL}$ sample mixed solution,

$A_{3}$ - the absorbance of the control group containing $2 \mathrm{~mL} \mathrm{95 \%} \mathrm{ethanol} \mathrm{and} 2 \mathrm{~mL}$ DPPH solution.

The ability to chelate iron $\left(\mathrm{Fe}^{2+}\right) .0 .5 \mathrm{~mL}$ of the sample solution to be tested was placed in a test tube, $1 \mathrm{~mL}$ $\mathrm{FeCl}_{2}(0.02 \mathrm{mmol} / \mathrm{L})$ and $1 \mathrm{~mL}$ ferrozine $(0.5 \mathrm{mmol} / \mathrm{L})$ were added in turn and thoroughly mixed in a vortex blender. After being placed at room temperature for $10 \mathrm{~min}$, the absorbance value $A_{1}$ was measured at $562 \mathrm{~nm}$. Distilled water was used as a control instead of the sample. The chelating capacity was calculated as follow (Kong and Xiong, 2006):

$$
\text { Chelating rate }=\frac{A_{2}-A_{1}}{A_{2}} \times 100 \%
$$

where:
$A_{1}$ - the absorbance at $562 \mathrm{~nm}$ of sample,

$A_{2}$ - the absorbance at $562 \mathrm{~nm}$ of control.

Hydroxyl radical scavenging rate. $1 \mathrm{~mL}$ of the sample solution was taken to be tested and put into a test tube, equal volumes of $\mathrm{FeSO}_{4}(9 \mathrm{mmol} / \mathrm{L})$ and $\mathrm{H}_{2} \mathrm{O}_{2}(10 \mathrm{mmol} / \mathrm{L})$ were added in turn and mixed well in a vortex mixer. They were then incubated at $37^{\circ} \mathrm{C}$ for $10 \mathrm{~min}$, then $1 \mathrm{~mL}$ of salicylic acid solution $(9 \mathrm{mmol} / \mathrm{L})$ was added and they were incubated for $30 \mathrm{~min}$. The absorbance was measured at $510 \mathrm{~nm}$ as $A_{1}$. Distilled water was used as a control instead of the sample (Li et al., 2015).

$$
\text { Hydroxyl radical scavenging rate }=\frac{A_{2}-A_{1}}{A_{2}} \times 100 \%
$$

where:

$A_{1}$ - the absorbance at $510 \mathrm{~nm}$ of sample,

$A_{2}$ - the absorbance at $510 \mathrm{~nm}$ of control.

Total reduction force. $2.5 \mathrm{~mL}$ of the sample solution was taken to be tested and put into a test tube. 0.2 $\mathrm{mmol} / \mathrm{L}$ phosphoric acid buffer solution $(\mathrm{pH}=6.6)$, $1 \%$ potassium ferricyanide solution and $10 \%$ trichloroacetic acid solution of equal volume were added in turn and mixed well in a vortex mixer. They were mixed well and their absorbance at $700 \mathrm{~nm}$ was measured. There was a positive correlation between absorbance and reduction ability (Dorman, et al., 2004).

\section{RESULTS AND DISCUSSIONS}

\section{The effects of reconstituted milk concentration on the antioxidative activity of goat milk fermented by Lactobacillus casei $L 61$}

$50 \mathrm{~mL}$ of reconstituted goat milk with $5,7,9,11,13 \%$ $(\mathrm{w} / \mathrm{v})$ concentration was prepared and sub packed in a $100 \mathrm{~mL}$ anaerobic flask. It was sterilized in a $90^{\circ} \mathrm{C}$ constant temperature water bath for 15 minutes and taken out. After this, it was cooled to room temperature, the activated Lactobacillus casei L61 was added to it according to $6 \%(\mathrm{v} / \mathrm{v})$ inoculation amount, and then it was fully mixed and fermented in a $41^{\circ} \mathrm{C}$ constant temperature water bath for $14 \mathrm{~h}$. It was taken out after fermentation and centrifugated to prepare the whey supernatant sample. The DPPH radical scavenging activity, chelate iron ion activity, hydroxyl radical 


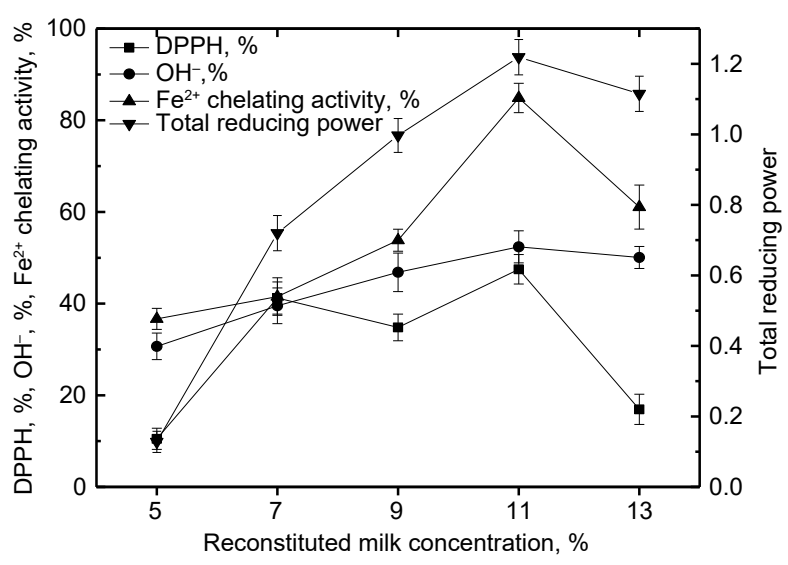

Fig. 1. Effects of goat milk density on antioxidant ability

scavenging activity and total reducing power were determined. The results are shown in Figure 1.

It can be seen from Figure 1 that the concentration of reconstituted milk has a significant impact on the ability of goat milk to produce antioxidant peptides. With an increase in the concentration of reconstituted milk, chelating iron ion capacity, and hydroxyl radical scavenging rate, total reducing power first increased and then decreased. When the concentration of reconstituted milk reached $11 \%$, the DPPH scavenging rate hydroxyl radical scavenging rate and total reducing power reached the maximum, which were $84.87 \%$, $52.38 \%$ and 1.22 , respectively. With an increase in reconstituted milk concentration, DPPH radical scavenging activity first increased and then decreased and then increased, and when the concentration was $11 \%$, it reached the maximum value of $47.49 \%$. It can be seen that an $11 \%$ concentration of reconstituted milk is the best result of a single factor. This is because, under the same conditions, increasing the concentration of the reaction substrate is conducive to promoting the reaction. When the concentration of reconstituted milk is too high, it will inhibit the protease production of Lactobacillus casei L61, which will reduce the content of antioxidant peptides and reduce the activity.

\section{The effects of the inoculation amount of Lactobacillus casei L61 on the antioxidation of fermented milk}

The activated Lactobacillus casei L61 was inoculated into $11 \%$ reconstituted goat milk according to $2 \%$,

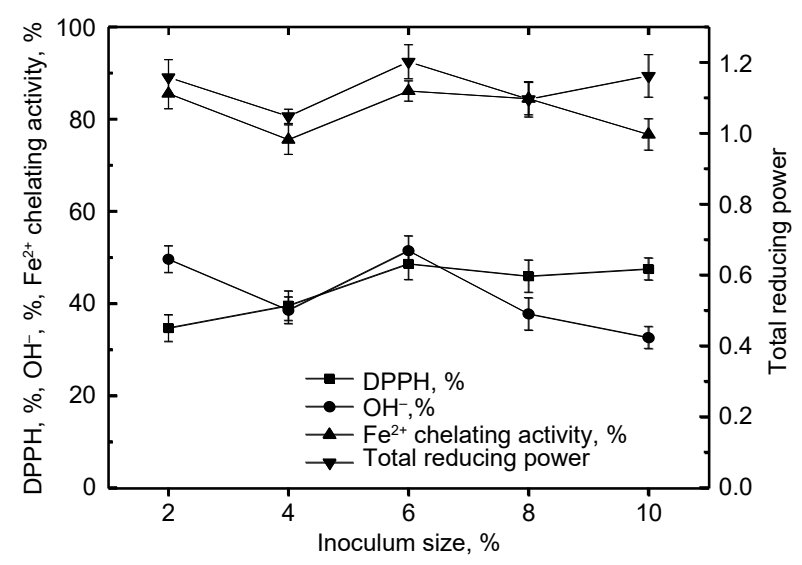

Fig. 2. Effects of inoculum on antioxidant ability

$4 \%, 6 \%, 8 \%, 10 \%$ respectively. The goat milk was well blended and fermented at $41^{\circ} \mathrm{C}$ for 14 hours to prepare the supernatant sample of whey. The DPPH free radical scavenging rate, chelating iron ion ability, hydroxyl free radical scavenging rate and total reducing power were measured. The results are shown in Figure 2.

It can be seen from Figure 2 that with an increase in inoculation amount, the chelating iron ion capacity and hydroxyl radical scavenging activity show a trend of decreasing first, then increasing and then decreasing. When the inoculation amount reaches $6 \%$, the scavenging rate of free radicals reaches the maximum, which is $86.11 \%$ and $51.46 \%$ respectively; when the concentration of recovered milk increases, the scavenging rate of DPPH radical first increases and then decreases, which also reaches the maximum value of $48.13 \%$ when the inoculation amount is $6 \%$. It can be seen from the change trend of the total reducing power that when the inoculation amount reaches $10 \%$, the total reducing power reaches the maximum. Therefore, $6 \%$ inoculation amount was selected as the best condition for single factor. This is because when the reaction substrate is fixed, Lactobacillus case $i$ L61 in a certain range can make full use of the substrate to produce antioxidant peptides; when the number of bacteria continues to increase, it is difficult for the substrate to meet the needs of more microbial growth, and it is possible to decompose and utilize the generated antioxidant peptides so as to reduce the antioxidant activity. 


\section{The effects of fermentation time on the antioxidation of fermented milk by L. casei L61}

L61 activation solution was added to an $11 \%$ reconstituted milk medium according to a $6 \%$ inoculation amount. The mixture was well mixed and fermented at $41^{\circ} \mathrm{C}$ for $8,10,12,14$ and 16 hours to prepare the supernatant sample of whey, and a fermentation for $0 \mathrm{~h}$ was designed as the control group. The DPPH radical scavenging rate, chelating iron ion ability, hydroxyl radical scavenging rate and total reducing power were measured. The results are shown in Figure 3.

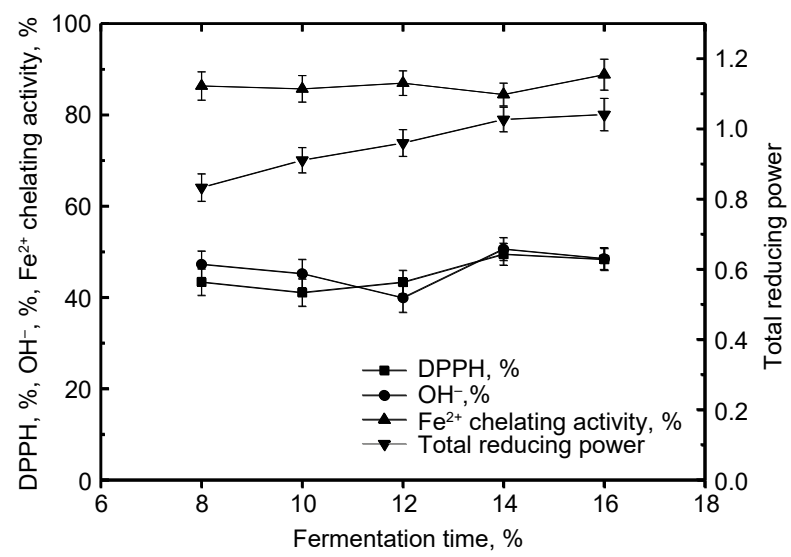

Fig. 3. Effects of fermenting time on antioxidant ability

From Figure 3, it appears that DPPH scavenging rate and hydroxyl scavenging rate decreased first, then increased and then decreased with an increase in fermentation time. When the fermentation time reached $14 \mathrm{~h}$, DPPH scavenging rate and hydroxyl scavenging rate reached the maximum, $49.47 \%$ and $50.60 \%$ respectively, while the scavenging rate of DPPH free radical in the control group was $32.23 \%$. The antioxidant activity of the experimental group was significantly higher than that of the control group. The ability to chelate iron ion showed a trend of decreasing first and then increasing; when the fermentation time was $16 \mathrm{~h}$, the ability to chelate iron ion reached the maximum of $84.67 \%$; when the fermentation time reached $14 \mathrm{~h}$, the total reducing power reached the maximum of 1.06. Based on the above results, the optimal fermentation time of $14 \mathrm{~h}$ was determined.

\section{The effects of temperature on the antioxidative activity of fermented milk by $L$. casei $L 61$}

L61 activation solution was added to an $11 \%$ reconstituted milk medium according to a $6 \%$ inoculation amount. It was mixed evenly, put in a constant temperature water bath at $35^{\circ} \mathrm{C}, 37^{\circ} \mathrm{C}, 39^{\circ} \mathrm{C}, 41^{\circ} \mathrm{C}$ and $43^{\circ} \mathrm{C}$ for $14 \mathrm{~h}$, then taken out and prepared for the whey sample. The DPPH radical scavenging rate, chelating iron ion ability, hydroxyl radical scavenging rate and total reducing power were measured. The results are shown in Figure 4.

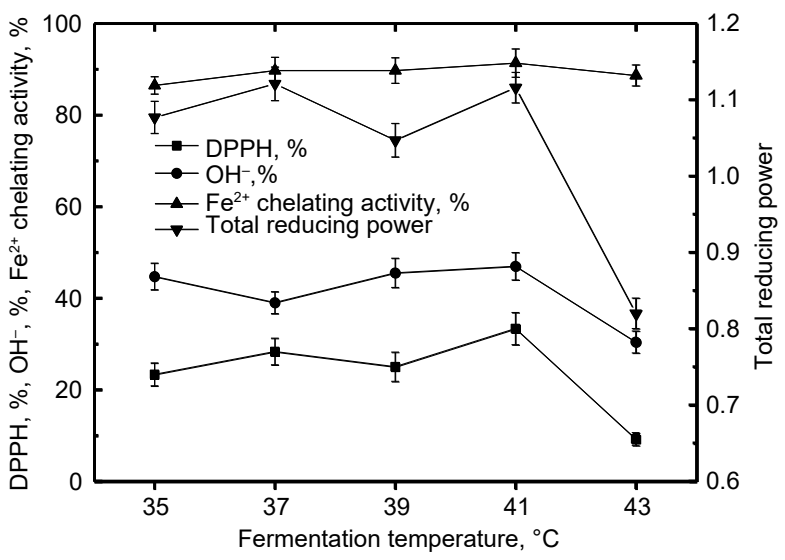

Fig. 4. Effects of temperature on antioxidant ability

As can be seen from Figure 4, the antioxidant indexes of the four groups showed a trend of increasing first and then decreasing. When the fermentation temperature was $41^{\circ} \mathrm{C}$, the antioxidant activity was stronger, the scavenging rate of DPPH radical, chelating iron ion ability, scavenging rate of hydroxyl radical and total reducing power were $35.87 \%, 90.34 \%$, $46.69 \%$ and 1.14 , respectively.

\section{The optimization of fermentation conditions for antioxidant peptide production by Lactobacillus casei L61 by orthogonal test}

The effects of inoculation amount, concentration of reconstituted milk, fermentation temperature and fermentation time on the antioxidation of fermented milk by $L$. case $i$ L61 were investigated. The optimum single factor conditions were determined as follows: 
Chen, H., Mao, Y., Du, G., Li, X., Liu, Z., Kou, J. (2020). The optimization of peptides - producing conditions for antioxidant peptides in goat milk by Lactobacillus casei L61. Acta Sci. Pol. Technol. Aliment., 19(2), 169-176. http://dx.doi.org/10.17306/J.AFS.2020.0753

inoculation amount $6 \%$, concentration of reconstituted milk $11 \%$, fermentation temperature $41^{\circ} \mathrm{C}$, and fermentation time $14 \mathrm{~h}$. According to the results of the single factor experiment, taking the reconstituted milk concentration $(A)$, inoculation amount $(B)$, fermentation time $(C)$ and fermentation temperature $(D)$ as variables, DPPH scavenging rate $(Y)$ as indicators, four factors and three levels of orthogonal experiment were designed to determine the best combination of fermentation conditions for the production of antioxidant peptides, and the orthogonal results were analyzed. The results are shown in Table 1 and Table 2. The control group had inoculation 5\%, reconstituted milk concentration $10 \%$, fermentation temperature $41^{\circ} \mathrm{C}$, fermentation time 12.3 hours.

$K_{1}, K_{2}$ and $K_{3}$ are the sum of index of factor level 1, 2 and 3 respectively. The mean value is expressed by $k$, and $k_{1}$, and $k_{2}$ and $k_{3}$ are the average of experimental results at each level respectively. The range, $R$, reflects the effects of various factors in the experiment. The larger the $R$ value, the higher the significance of the corresponding factor and the greater the influence on the experimental index. The highest value of $k$ in each factor constitutes the optimal horizontal combination. It can be seen from the analysis of the range of orthogonal test results in Table 1 that each factor has a certain impact on the production of antioxidant peptides in fermented goat milk, among which the inoculation amount of bacteria has the most significant impact on the DPPH scavenging rate of fermented goat milk, and the significant effect of each factor on DPPH clearance rate was $B>A>C>D$, that is, the inoculation amount $>$ reconstituted milk concentration $>$ fermentation time $>$ fermentation temperature, and the best combination was $A_{1} B_{2} C_{3} D_{3}$, that is, the concentration of reconstituted milk was $11 \%$, the inoculation amount was $5 \%$, the fermentation time was $16 \mathrm{~h}$, and the fermentation temperature was $41^{\circ} \mathrm{C}$.

From the results of ANOVA in Table 2, it can be seen that the $F$ values of the reconstituted milk concentration $(A)$ and inoculation amount $(B)$ were 7.062 and 34.783, respectively, which had significant effects compared with the $F_{0.05}$ values. Among them, the inoculation amount had the most significant effect on the results, while fermentation time and temperature had no significant effect. The results of ANOVA were consistent with those of the range analysis. So, the optimal
Table 1. Results of orthogonal experiment on fermenting conditions of Lactobacillus casei L61

\begin{tabular}{|c|c|c|c|c|c|}
\hline \multirow{2}{*}{$\begin{array}{c}\text { Trial } \\
\text { no. }\end{array}$} & \multicolumn{4}{|c|}{ Factor number } & \multirow{2}{*}{$Y, \%$} \\
\hline & $A, \%$ & $B, \%$ & $C, \mathrm{~h}$ & $D,{ }^{\circ} \mathrm{C}$ & \\
\hline 1 & $1(11)$ & $1(4)$ & $1(14)$ & $1(37)$ & 46.31 \\
\hline 2 & 1 & $2(5)$ & $2(15)$ & $2(39)$ & 56.62 \\
\hline 3 & 1 & $3(6)$ & $3(16)$ & $3(41)$ & 56.91 \\
\hline 4 & $2(12)$ & 1 & 2 & 3 & 42.50 \\
\hline 5 & 2 & 2 & 3 & 1 & 53.96 \\
\hline 6 & 2 & 3 & 1 & 2 & 49.13 \\
\hline 7 & $3(13)$ & 1 & 3 & 2 & 46.17 \\
\hline 8 & 3 & 2 & 1 & 3 & 54.33 \\
\hline 9 & 3 & 3 & 2 & 1 & 53.26 \\
\hline$K_{1}$ & 159.840 & 134.979 & 149.769 & 153.531 & \\
\hline$K_{2}$ & 145.590 & 164.910 & 152.379 & 151.920 & \\
\hline$K_{3}$ & 153.769 & 159.300 & 157.041 & 153.741 & \\
\hline$k_{1}$ & 53.280 & 44.993 & 49.923 & 51.177 & \\
\hline$k_{2}$ & 48.530 & 54.970 & 50.793 & 50.640 & \\
\hline$k_{3}$ & 51.253 & 53.100 & 52.347 & 51.247 & \\
\hline$R$ & 4.750 & 9.977 & 2.424 & 0.607 & \\
\hline Best & $A_{1} B_{2} C_{3} D_{3}$ & & & & \\
\hline
\end{tabular}

Table 2. The ANOVA of DPPH scavenging rate

\begin{tabular}{lrrrc}
\hline Factors & \multicolumn{1}{c}{ SS } & DF & $F$-value & $F_{0.05}$ \\
\hline$A$ & 34.086 & 2 & $7.026^{*}$ & 6.940 \\
$B$ & 168.749 & 2 & $34.783^{*}$ & 6.940 \\
$C$ & 9.042 & 2 & 1.864 & 6.940 \\
$D$ & 0.661 & 2 & 0.136 & 6.940 \\
Residual & 9.70 & 4 & & \\
\hline
\end{tabular}

$\mathrm{SS}$ - sum of squares, DF - degree of freedom.

combination of orthogonal test was $B_{2} A_{1} \mathrm{C}_{3} D_{3}$, that is, the concentration of reconstituted milk was $11 \%$, the inoculation amount was $5 \%$, the fermentation time was $16 \mathrm{~h}$, and the fermentation temperature was $41^{\circ} \mathrm{C}$. 
Jia, Bo and Li (2002) investigated the preparation of antimicrobial peptides from 15 strains of Lactobacillus plantarum fermented starch, screened one strain of Lactobacillus plantarum, and studied the fermentation time of its peptide production (Jia et al., 2002). The peptide activity was measured every 5 hours. The experimental results showed that the peptide activity reached the maximum at 15 hours of fermentation, and began to decline after 15 hours, which was basically consistent with the influence of fermentation time on the production of antioxidant peptides in this study. Therefore, as the fermentation time continues to extend, the peptide production capacity will decline. Zhang studied the clotting effects of 123 kinds of lactobacilli, selected three Lactobacillus strains CH9-34.0, SH34.3 and SB5 from them, and optimized their fermentation conditions for protease production, and determined that the optimal reaction temperature of protease was $42^{\circ} \mathrm{C}$ (Zhang, 2014). It can be seen that temperatures which are too high will lead to the inactivation of protease and affect its ability to produce antioxidant peptides. At the same time, high temperatures can inhibit or even kill the growth of bacteria, so it shows the decline of antioxidant activity.

The results showed that the DPPH radical scavenging rate of the whey sample was $59.97 \pm 0.87 \%$, which was higher than that of the above 9 groups, and significantly higher than that of the control group $(41.97 \pm 1.37 \%)$. Therefore, it is reliable to optimize the fermentation conditions of Lactobacillus casei L61 by orthogonal test. The importance and benefits of antioxidants are well known. This study provides more methods and theoretical basis for the preparation of safe antioxidants and also paves the way for the preparation of antioxidant foods such as antioxidant milk powder and dairy products.

\section{CONCLUSION}

The optimal fermentation conditions for the production of antioxidant peptides by Lactobacillus casei L61 were a reconstituted milk concentration of $11 \%$, an inoculum amount of $5 \%$, a fermentation temperature of $41^{\circ} \mathrm{C}$, and a fermentation time of 16 hours. The DPPH scavenging rate of the fermented milk was $59.97 \pm 0.87 \%, 18 \%$ higher than that of the control group $(41.97 \pm 1.37 \%)$.

\section{REFERENCES}

Abeyrathne, E. D. N. S., Huang, X., Ahn, D. U. (2018). Antioxidant, angiotensin-converting enzyme inhibitory activity and other functional properties of egg white proteins and their derived peptides - a review. Poultry Sci., 97(4), 1462-1468. https://doi.org/10.3382/ps/pex399

Bao, Y. H., Li, R. D., Wang, G., Liang, X., Qin, L. (2009). Preparation of whey antioxidant peptides by microbial fermentation. China Dairy Ind., 37(10), 11-14.

Clancy, D., Birdsall, J. (2013). Flies, worms and the free radical theory of ageing. Ageing Res. Rev., 12(1), 404412. https://doi.org/10.1016/j.arr.2012.03.011

Das, S. K. (2016). Special issue on "free radicals and antioxidants in health \& diseases" preface. Indian J. Exp. Biol., 54(11), 681-683.

Dorman, H. J. D., Bachmayer, O., Kosar, M., Hiltunen, R. (2004). Antioxidant properties of aqueous extracts from selected lamiaceae species grown in Turkey. J. Agric. Food Chem., 52(4), 762-770. https://doi.org/10.1021/ jf034908v

Elfahri, K. R., Vasiljevic, T., Yeager, T., Donkor, O. N. (2016). Anti-colon cancer and antioxidant activities of bovine skim milk fermented by selected Lactobacillus helveticus strains. J. Dairy Sci., 99(1), 31-40. https:// doi.org/10.3168/jds.2015-10160

Goodman, D. L., McDonnell, J. T., Nelson, H. S., Vaughan, T. R., Weber, R. W. (1990). Chronic urticaria exacerbated by the antioxidant food preservatives, butylated hydroxyanisole (BHA) and butylated hydroxytoluene (BHT). J. Allergy Clin. Immun., 86(4), 570-575. https:// doi.org/10.1016/s0091-6749(05)80214-3

Guo, Y. X. (2003). Study on the preparation of bioactive peptides from whey powder by microbial fermentation. Tianjin: Tianjin Business University.

Harman, D. (2006). Free radical theory of aging: An update: Increasing the functional life span. Ann. New York Acad. Sci., 1067, 10-21.https://doi.org/10.1196/annals.1354.003

Jia, J. B., Bo, C. W., Li, D. (2002). Breeding and fermentation conditions of antimicrobial peptide producing bacteria. Res. Discus., 12(1), 23-27.

Kitts, D. D., Weiler, K. (2003). Bioactive proteins and peptides from food sources. Applications of bioprocesses used in isolation and recovery. Curr. Pharm. Design, 9(16), 1309-1323. https://doi.org/10.2174/1381612033454883

Kong, B., Xiong, Y. L. (2006). Antioxidant activity of zein hydrolysates in a liposome system and the possible mode of action. J. Agric. Food Chem., 54(16), 60596068. https://doi.org/10.1021/jf060632q 
Chen, H., Mao, Y., Du, G., Li, X., Liu, Z., Kou, J. (2020). The optimization of peptides - producing conditions for antioxidant peptides in goat milk by Lactobacillus casei L61. Acta Sci. Pol. Technol. Aliment., 19(2), 169-176. http://dx.doi.org/10.17306/J.AFS.2020.0753

Li, Y., Liu, T., He, G. (2015). Antioxidant activity of peptides from fermented milk with mix culture of lactic acid bacteria and yeast. Adv. J. Food Sci. Technol., 7(6), 422-427. https://doi.org/10.19026/ajfst.7.1335

Lorenzo, J. M., Munekata, P. E. S., Gómez, B., Barba, F. J., Mora, L., Pérez-Santaescolástica, C., Toldrá, F. (2018). Bioactive peptides as natural antioxidants in food products - A review. Trends Food Sci. Technol., 79, 136147. https://doi.org/10.1016/j.tifs.2018.07.003

Panchal, G., Hati, S., Sakure, A. (2020). Characterization and production of novel antioxidative peptides derived from fermented goat milk by $L$. fermentum. LWT-Food Sci. Technol., 119. https://doi.org/10.1016/j. lwt.2019.108887

Park, P. J., Jung, W. K., Nam, K. S., Shahidi, F., Kim, S. K. (2001). Purification and characterization of antioxidative peptides from protein hydrolysate of lecithin-free egg yolk. J. Am. Oil Chem. Soc., 78(6), 651-656. https://doi.org/10.1007/s11746-001-0321-0

Persichetti, E., De Michele, A., Codini, M., Traina, G. (2014). Antioxidative capacity of Lactobacillus fermentum LF31 evaluated in vitro by oxygen radical absorbance capacity assay. Nutrition, 30(7-8), 936-938. https://doi.org/10.1016/j.nut.2013.12.009

Ramesh, V., Kumar, R., Singh, R. R. B., Kaushik, J. K., Mann, B. (2012). Comparative evaluation of selected strains of lactobacilli for the development of antioxidant activity in milk. Dairy Sci. Technol., 92(2), 179-188. https://doi.org/10.1007/s13594-011-0048-Z

Shu, G., Mei, S., Chen, L., Cao, B., Zhang, Q., Chen, H., Cui, X. (2019). Optimization of the antioxiant peptides production from goat milk casein hydrolyzed by alcalase and papain using respons surface methodology. Ann. Univ. Dunarea de Jos of Galati Fascicle VI - Food Technol., 43(1), 24-39. https://doi.org/10.35219/foodtechnology.2019.1.02

Sila, A., Bougatef, A. (2016). Antioxidant peptides from marine by-products: Isolation, identification and application in food systems. A review. J. Funct. Foods, 21, 10-26. https://doi.org/10.1016/j.jff.2015.11.007

Virtanen, T., Pihlanto, A., Akkanen, S., Korhonen, H. (2007). Development of antioxidant activity in milk whey during fermentation with lactic acid bacteria. J. Appl. Microbiol., 102(1), 106-115. https://doi.org/10.1111/j.13652672.2006.03072.x

Zeng, W.-C., Zhang, Z., Gao, H., Jia, L.-R., Chen, W.-Y. (2012). Characterization of antioxidant polysaccharides from Auricularia auricular using microwave-assisted extraction. Carbohyd. Polym., 89(2), 694-700. https:// doi.org/10.1016/j.carbpol.2012.03.078

Zhang, S. (2014). Studies on the fermentation characteristics of Lactobacillus and the effect of its protease on the quality of curd. Harbin: Harbin University of Technology. 